\title{
Determination of the absolute depths of the mantle transition zone discontinuities beneath China: Effect of stagnant slabs on transition zone discontinuities
}

\author{
Fenglin Niu* and Hitoshi Kawakatsu \\ Earthquake Research Institute, University of Tokyo, 1-1-1 Yayoi, Bunkyo-ku, Tokyo 113-0032, Japan
}

(Received July 22, 1998; Revised September 21, 1998; Accepted October 6, 1998)

\begin{abstract}
Broadband seismic waveform data are stacked to investigate the mantle discontinuities beneath a station. A polarized filter is devised to remove pseudo-signals in the stacked traces, which might be otherwise misinterpreted as a discontinuity. The depth of a mantle discontinuity determined in previous studies depends on the reference model. We suggest the use of data sets which have a range of epicentral distances to the investigated station. The observed travel time of the P-to-S converted phases as a function of epicentral distance can be used to constrain the proper reference model. When the technique is applied to real data, we can determine the absolute depth of a discontinuity with an accuracy of approximately $\pm 10 \mathrm{~km}$. The method is applied to the broadband data of the CDSN stations. There is no significant depression observed for any of the stations except BJI, implying that the lateral scale of the trough in the ' $660-\mathrm{km}$ ' discontinuity under northeast China is smaller than suggested in previous SS precursors studies. Beneath station BJI, the '410-km' and '660-km' discontinuities are elevated $10 \mathrm{~km}$ and depressed $30 \mathrm{~km}$, respectively, resulting in an extremely thick transition zone. This may be attributed to the cold pacific plate that exists in the transition zone of the same region. Meanwhile, at station MDJ, where the subducted pacific plate is also found in the mantle transition zone, a multiple-discontinuity structure is observed rather than a depressed '660-km' discontinuity. At station SSE, there is no depression of the '660-km' discontinuity, suggesting that there is no significant difference of temperature at depths around $660 \mathrm{~km}$ between SSE and the average mantle.
\end{abstract}

\section{Introduction}

In recent tomographic models (Zhou and Clayton, 1990; van der Hilst et al., 1991; Fukao et al., 1992; Sakurai et al., 1995), large scale high-velocity anomalies (hereafter referred to as HVAs) are found in the mantle transition zone depths beneath the eastern China. The HVAs, which extend several thousands of kilometers, are usually attributed to the stagnant slabs originating at the western Pacific subduction zones. Recent waveform studies by Tajima et al. (1998), however, suggests that the real lateral scale of HVAs may be smaller. The HVAs are generally believed to be colder than the surrounding mantle, and the ' $660-\mathrm{km}$ ' discontinuity is anticipated to be depressed by tens of kilometers within the cold interior of the HVAs. Therefore, a detailed topographic map of the '660-km' discontinuity will help constrain the distribution of HVAs. The present topographic model of the ' $660-\mathrm{km}$ ' discontinuity, produced from using long-period SS precursors (Shearer and Masters, 1992; Shearer, 1993; Flanagan and Shearer, 1998), suggests that there is a 15 to $20-\mathrm{km}$ deep trough in the '660-km' discontinuity beneath northeast China, having a lateral scale of $\sim 1500 \mathrm{~km}$ by $5000 \mathrm{~km}$. The trough is confirmed by Revenaugh and Sipkin (1994) who examined multiple ScS phases crossing eastern China, although it is denied by the SS precursors study of Petersen et al. (1993). Recently Neele et al. (1997) point out that

\footnotetext{
${ }^{*}$ To whom correspondence should be addressed.
}

Copy right $($ C The Society of Geomagnetism and Earth, Planetary and Space Sciences (SGEPSS); The Seismological Society of Japan; The Volcanological Society of Japan; The Geodetic Society of Japan; The Japanese Society for Planetary Sciences. the observed large lateral scale of the trough in the ' $660-\mathrm{km}$ ' discontinuity actually may be nothing more than the longwavelength manifestation of a much smaller scale (several hundreds kilometers) deflection of the discontinuity within a subducted slab, due to the large Fresnel zone $(\sim 2000 \mathrm{~km})$ of the SS precursors. In this paper, we use P-to-S converted waves (hereafter referred to as $P_{d} s$ ) to determine the depth distribution of the mantle transition zone discontinuities beneath China. The first Fresnel zone of $P_{d} s$ at a depth of $660 \mathrm{~km}$ is a circle with a radius of approximately $200 \mathrm{~km}$ when the P-wave comes in vertically for the intermediateperiod ( $\sim 6 \mathrm{~s}$ ) data we use. The topographic maps of the mantle discontinuities we obtain are compared to the results of the SS precursors and tomographic studies.

As shown in Fig. 1, $P_{d} s$ travels almost the same ray path as that of the direct $\mathrm{P}$-wave before it converts to an $\mathrm{S}$ wave at a mantle discontinuity beneath the station. The travel time difference, $\delta t_{P_{d} s-P}$, between $P_{d} s$ and the direct P-wave, depends on the local depth of the discontinuity and velocities above it. Variation of source depth has almost no effect on this time difference. The relative amplitude of $P_{d} s$ to the direct $\mathrm{P}$-wave is determined mainly by the impedance contrast at the discontinuity and is hardly affected by the source mechanism. The amplitude of $P_{660} s$ predicted by the Iasp91 seismic velocity model (Kennett and Engdahl, 1991 ) is about 3 percent of the direct $P$-wave. Due to its low amplitude, $P_{d} s$ is difficult to identify.

The method we use was first suggested by Vinnik (1977). To determine the depth of a mantle discontinuity using $P_{d} s$, the SV (or radial) component seismograms are first stacked 


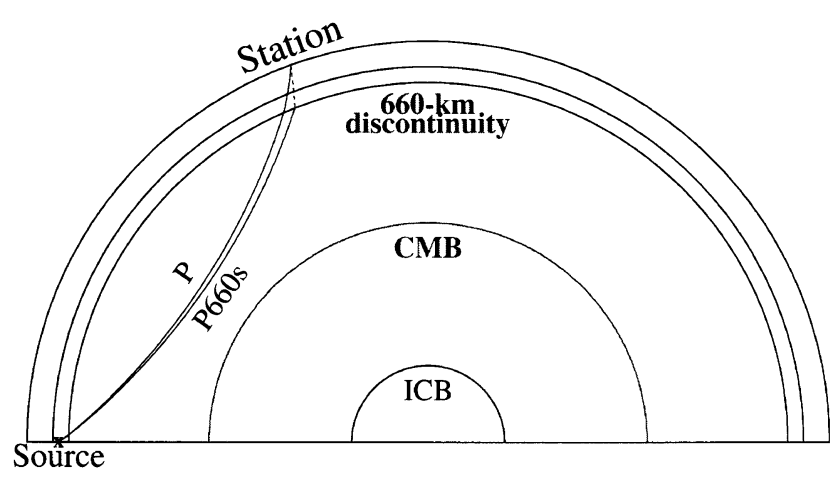

Fig. 1. Schematic illustration of ray paths of the direct P-wave and a P-to-S converted wave at a mantle discontinuity $\left(P_{660} s\right)$ beneath a station. The converted wave travels almost the same path as direct $\mathrm{P}$-wave before it converts to $\mathrm{S}$ wave at the '660-km' discontinuity beneath a station.

to identify the weak $P_{d} s$, the travel time difference between the detected $P_{d} s$ and the direct $\mathrm{P}$-wave is then measured from the stacked seismograms. Finally the observed travel time is transformed to the depth of the mantle discontinuity using a standard earth model (hereafter referred to as the reference model). There exist two problems in the above processing: the correct identification of $P_{d} s$ and the trade-off between the discontinuity depth and the reference model velocities. In this paper, we use a polarized filter which emphasizes signals having SV motion. The filter allows us to remove the possible pseudo-signals in the stacked seismograms and therefore makes the detection of the $P_{d} s$ more robust. We further measure the $\delta t_{P_{d} s-P}$ at several epicentral distances to constrain both the depth of the mantle discontinuity and the average velocity above it.

\section{Data Selection}

The data used in this study is the three component broadband waveform data recorded at the 11 stations of the Chinese Digital Seismic Network (CDSN, Fig. 2). The CDSN waveform data is a part of the FARM products provided by the IRIS Data Management Center. The coverage period of our data set is from January 1987 to December 1996 and magnitude (Mw) of events is $\geq 5.6$. To get a better signal-tonoise ratio, we limit our data sources to the deep events. We also exclude those events which have primary arrivals in the time window 30 80 sec after the first arrival, in which the weak $P_{d} s$ phases are expected to arrive. The selected events cluster into two epicentral distance ranges: $20^{\circ} \sim 40^{\circ}$ and $70^{\circ} \sim 90^{\circ}$ to the CDSN stations. The former corresponds to the deep events in the western Pacific subduction zones, and the later corresponds to the deep events in the Tonga subduction zone. For convenience, we will refer to these two clusters as non-Tonga and Tonga events, respectively, in the rest of the paper.

\section{Detection Technique}

Each record is decomposed to the vertical $(Z)$, radial $(R)$ and transverse $(T)$ components, low-pass filtered and deconvolved using the $P$ waveform of the same record. The deconvolved seismograms are then aligned so that the direct $\mathrm{P}$ - waves arrive at time zero. For an assumed P-to-S conversion depth of $d \mathrm{~km}$, the travel time of $P_{d} s$ for different epicentral distances and depths are calculated first by 1D ray-tracing using the Iasp91 model to determine the time correction of a seismogram before stacking. The assumed depth, $d$, is then varied in a certain depth range to determine whether a peak in the stacked seismograms is a P-to-S converted wave. In the following text, we will refer to this depth as "aligned depth", since it is a parameter used to align seismograms much like slowness in traditional stacking.

SV-Polarization filter. We vary the aligned depth $d$ from $300 \mathrm{~km}$ to $900 \mathrm{~km}$ in an increment of $10 \mathrm{~km}$, and stack the $Z$ - and $R$-component seismograms separately to produce 61 different pairs of stacked waveforms. For each pair of $Z$ - and $R$-component stacked seismograms, we first calculate the running average value of $R^{2} /\left(R^{2}+Z^{2}\right)$ within a time window of $6 \mathrm{sec}$, which is the cut-off period of the low-pass filtered data. The $R$-component stacked seismogram is multiplied by the above value to emphasize the SV motion. We show an example of stacked $Z$ - and $R$-component seismograms with the filtered traces in Fig. 3, in which the $P^{{ }^{\prime}} 410^{\prime} S$ and $P^{\prime} 660^{\prime} S$ seem to be more evident in the filtered traces.

Simultaneous determination of the depth and average velocity. The travel time difference, $\delta t_{P_{d} s-P}$, between $P_{d} s$ and the direct $\mathrm{P}$-wave, is a function of the depth of a discontinuity $d$, the velocity structure $v_{p}$ and $v_{s}$ above the discontinuity and the epicentral distance $\Delta$ :

$$
\delta t_{P_{d} s-P}=f\left(d, v_{p}, v_{s}, \Delta\right) .
$$

When $\delta t_{P_{d}-P}$ is available only at a single epicentral distance, there is no way to estimate the depth $d$ from $\delta t_{P_{d} s-P}$, other than assume a reference model. Consequently, the determined depth is model dependent. The depth of the ' $660-\mathrm{km}$ ' discontinuity will be over estimated as much as $20 \mathrm{~km}$ in the tectonic regions characterized by Grand and Helmberger (1984) and Walck (1984) models, if Iasp91 is used as the reference model. In Fig. 4, we show the theoretical travel time of $P^{\prime} 660^{\prime} S$ as a function of epicentral distance predicted by 3 different reference models based on Iasp91 but with varying discontinuity depth and velocity perturbations. The theoretical travel time is calculated at the average depth of all events. We see that travel time predicted by the different models have different slopes; a slow upper mantle model corresponds to a small slope while a fast upper mantle model corresponds to a large slope. In Fig. 4, we also show the observed travel time of $P^{\prime} 660^{\prime} s$ at station HIA (Neimenggu Province). Considering the error range in Fig. 4, it appears that models with lower velocity upper mantle are better able than Iasp91 model to explain observed $\delta t_{P^{{ }^{6} 60^{\prime}}} s-P$, and in the real calculation we used a model with a $1 \%$ lower velocity upper mantle. This demonstrates how the reference model can be obtained when $\delta t_{P_{d} s-P}$ can be obtained in a wide epicentral distances range assuming that there is no significant lateral heterogeneity beneath a station. Because our data includes two groups, the Tonga and non-Tonga deep events, it is therefore theoretically possible to constrain both the depth and the reference model simultaneously. If both $P^{\star} 410^{\prime} S$ and $P^{\prime} 660^{\prime} s$ are observed from the stacked waveforms of the two groups, then we can constrain the average velocity of the upper mantle above the '410-km' discontinuity as well as the 


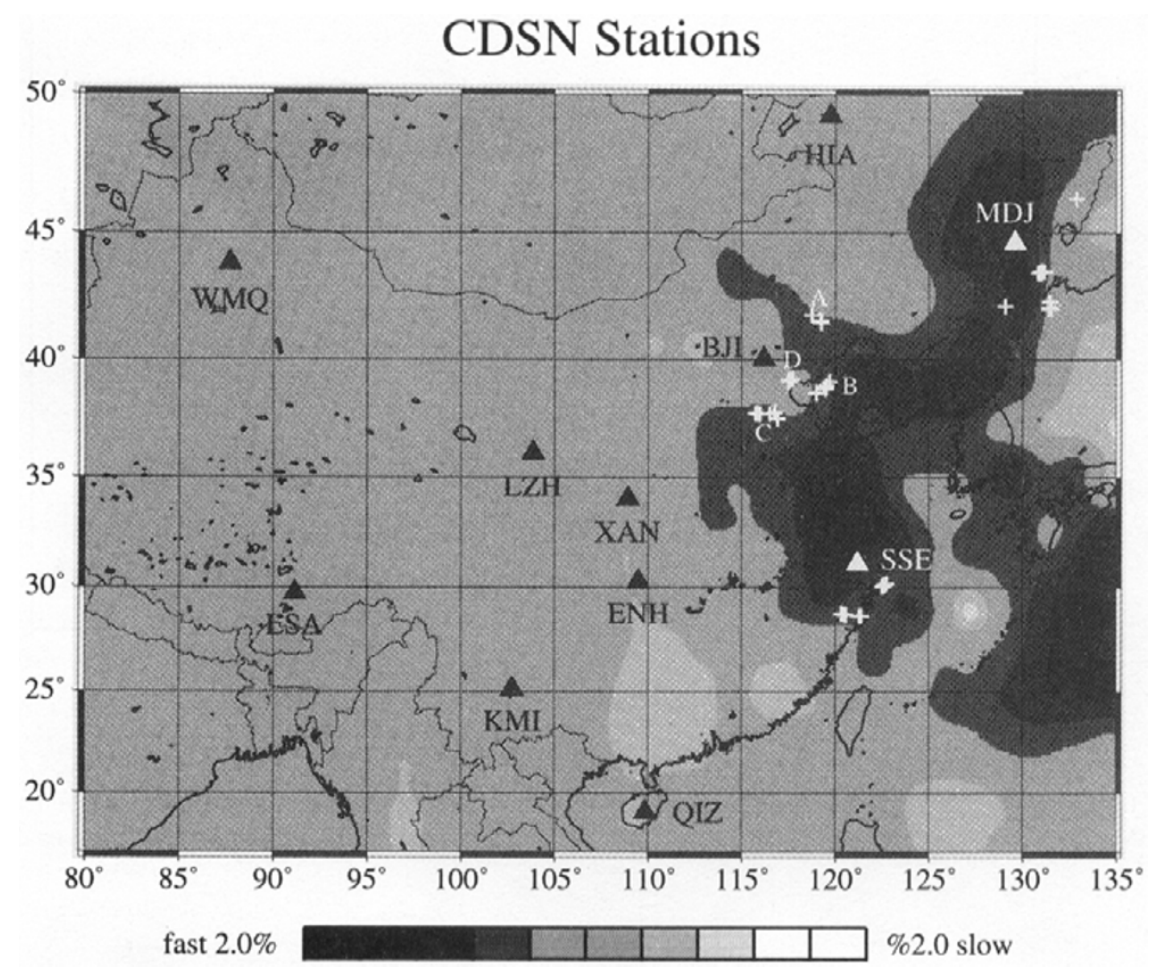

Fig. 2. Geographic distribution of the CDSN broadband stations, together with the deep transition zone layer (629 712 km) of the tomographic model (Sakurai et al., 1995). P-to-S conversion points at depth $660 \mathrm{~km}$ for stations BJI, MDJ and SSE are shown by '+ '.
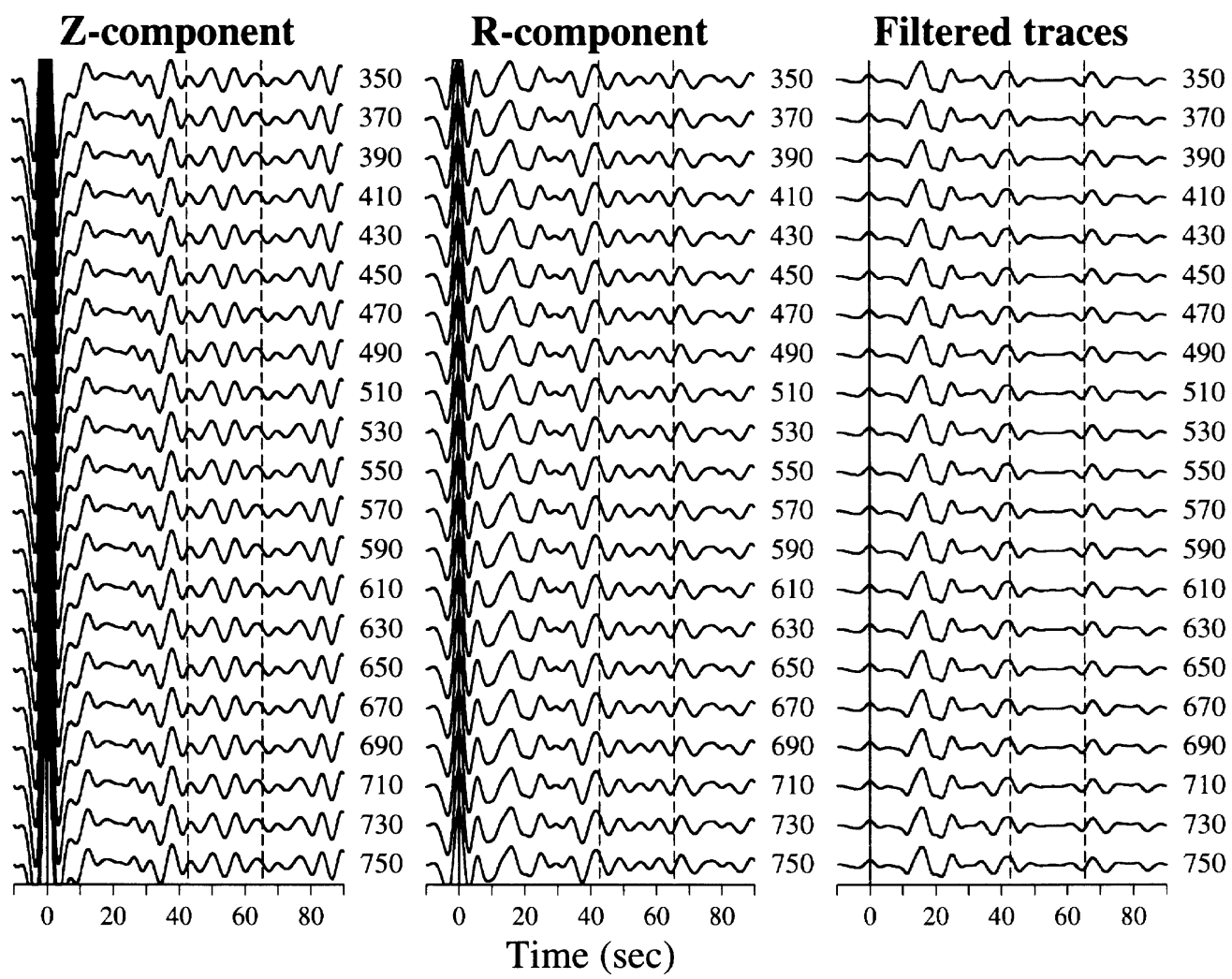

Fig. 3. Stacked traces of the deep Tonga events at station BJI. (left) $Z$-component; (middle) $R$-component; (right) filter traces. 


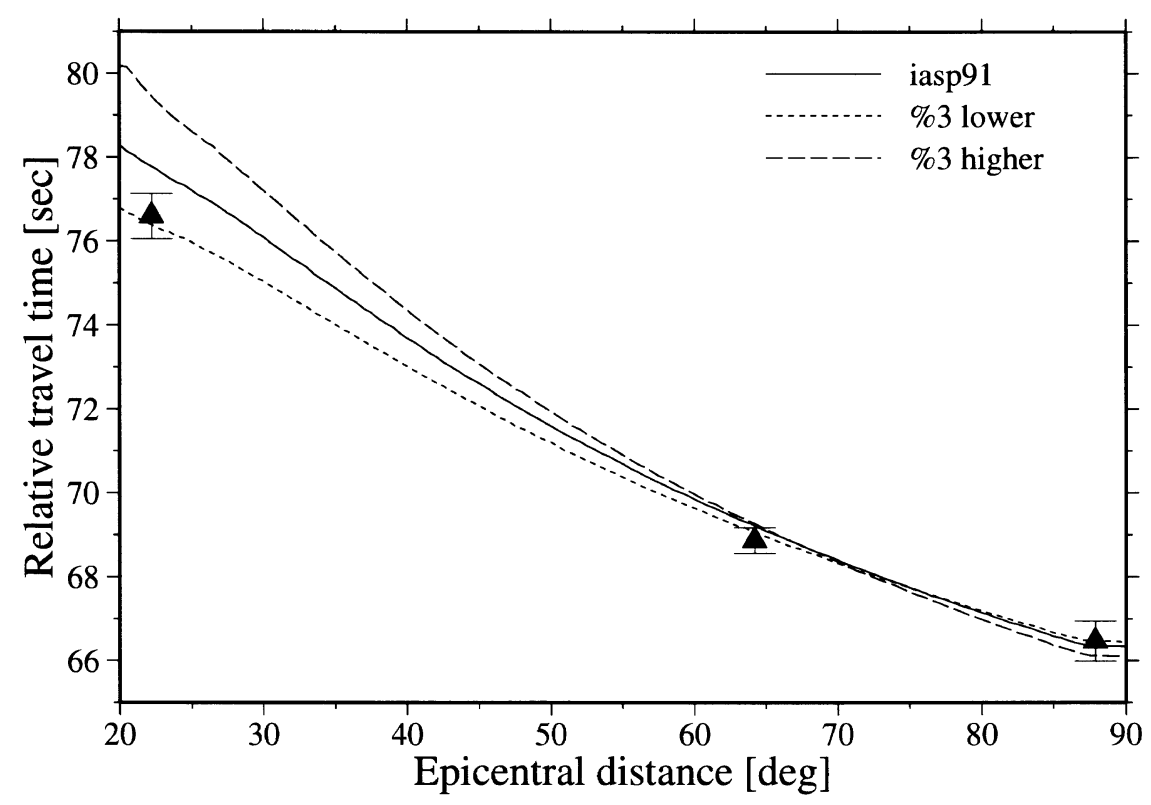

Fig. 4. Theoretical travel time of $P^{،} 660^{\prime} S$ with respect to the direct $\mathrm{P}$ wave predicted by 3 different reference models as a function of epicentral distance. Note that different mantle models have different slopes. The observed $\delta t_{P^{*} 660^{\prime}} s-P$ for the station HIA is also shown as an example.

transition zone. However, if $P^{\prime} 410^{\prime} s$ is observed only at one distance, then we can only obtain the average velocity of the whole upper mantle.

In the tomographic model of Sakurai et al. (1995) (hereafter referred to as the tomographic model) HVAs exist in the mantle transition zone depths beneath 3 stations; BJI, MDJ and SSE (Fig. 2). We note that even though station BJI is situated above a almost normal transition zone, the conversion points of $P^{\prime} 660^{\prime} s$, located approximately $200 \mathrm{~km}$ southeast of the station, are inside a HVA (Fig. 2). In the following sections, we will mainly discuss the discontinuity structure beneath these 3 stations to constrain the possible effect of subducted slabs.

\section{Observation of the Mantle Discontinuities be- neath China}

BJI. The stacked waveforms of the 7 Tonga events and 22 non-Tonga events at station BJI (Beijing) are shown in Figs. 5(a) and 5(b), respectively. Two arrivals at 41.9 and $67.6 \mathrm{sec}$ (arrows) can be found in Fig. 5(a), the poor sensitivity of the two signals to the aligned depth is due to the small epicentral distance range of the Tonga events. In Fig. 5(b), the signal at $77.0 \mathrm{sec}$ has a peak amplitude at an aligned depth of $690 \mathrm{~km}$, and is therefore identified as $P^{\prime} 660^{\prime} S$. The signal around $40 \mathrm{sec}$ has a very complicated waveform with a maximum amplitude at the aligned depth of $300 \mathrm{~km}$. As shown in the Fig. 2, the conversion points of the non-Tonga group (clusters as labeled by A, B, C) are much more scattered than that of the Tonga group (cluster D), therefore the complicated waveform can be due to lateral heterogeneity between the conversion points. Even though we stack separately the seismograms of the clusters A, B and C, which should not be affected by lateral heterogeneity, there is still no evident $P^{\prime} 410^{\prime} s$ in the stacked traces. On the other hand, synthetic seismograms using the Thomson-Haskell method
(Haskell, 1962) suggest that SV-seismograms till $\sim 40 \mathrm{sec}$ after the direct $\mathrm{P}$ can be contaminated severely by crustal reverberation and other shallow structure, such as a velocity decrease at a depth of $\sim 330 \mathrm{~km}$ suggested by Revenaugh and Sipkin (1994). Therefore identification of $P^{\bullet} 410^{\prime} S$ is much more difficult than $P^{\circ} 660^{\prime} s$, and most of our observation of $P^{\prime} 410^{\prime} s$ is only at one distance.

In Fig. 6, the observed time of $P^{،} 660^{\prime} S$ is shown as a function of epicentral distance, with the theoretical travel time of $P_{690} s$ predicted by Iasp91 shown by a solid line. We also show the theoretical travel time of $P_{670} S$ and $P_{710} s$ predicted by the two revised Iasp91 velocity models with $3 \%$ higher and lower velocity upper mantle, respectively. The error bar shown in Fig. 6 is evaluated by a delete- $d$ jackknife method (e.g., Efron and Tibshirani, 1986; Koch, 1992). A total of 500 data subsets, each consisting of $80 \%$ of the seismograms randomly selected from the two groups, are made and stacked. The standard error for a delete- $d$ jackknife estimate is $f \cdot \sigma$, where $\sigma$ is the standard deviation of the 500 observed arrival times. When the total number $n$ and dropped number $d$ satisfies that $n^{1 / 2} / d \rightarrow 0$ and $n-d \rightarrow \infty$, the factor $f$ is:

$$
f=\left(\frac{n-d}{d}\right)^{\frac{1}{2}} \text {. }
$$

The total number $n$ of our data as listed in Table 1, however, is not so large and the above relation is not restrictively satisfied, therefore Eq. (2) can not be used to estimate $f$. We vary $d$ from $50 \%$ to $90 \%$ of the total number $n$ and calculate the standard deviation $\sigma$. There is no significant change of the $\sigma$, and $f$ is about 1.2 when $d$ is $20 \%$ of the total events. From Fig. 6, we can see that Iasp91 seems to be better than the other two models at explaining the observed data.

As the average upper mantle velocity is known, the Pto-S conversion depth can be determined exactly from the observed travel time data. In Fig. 7, the normalized ampli- 

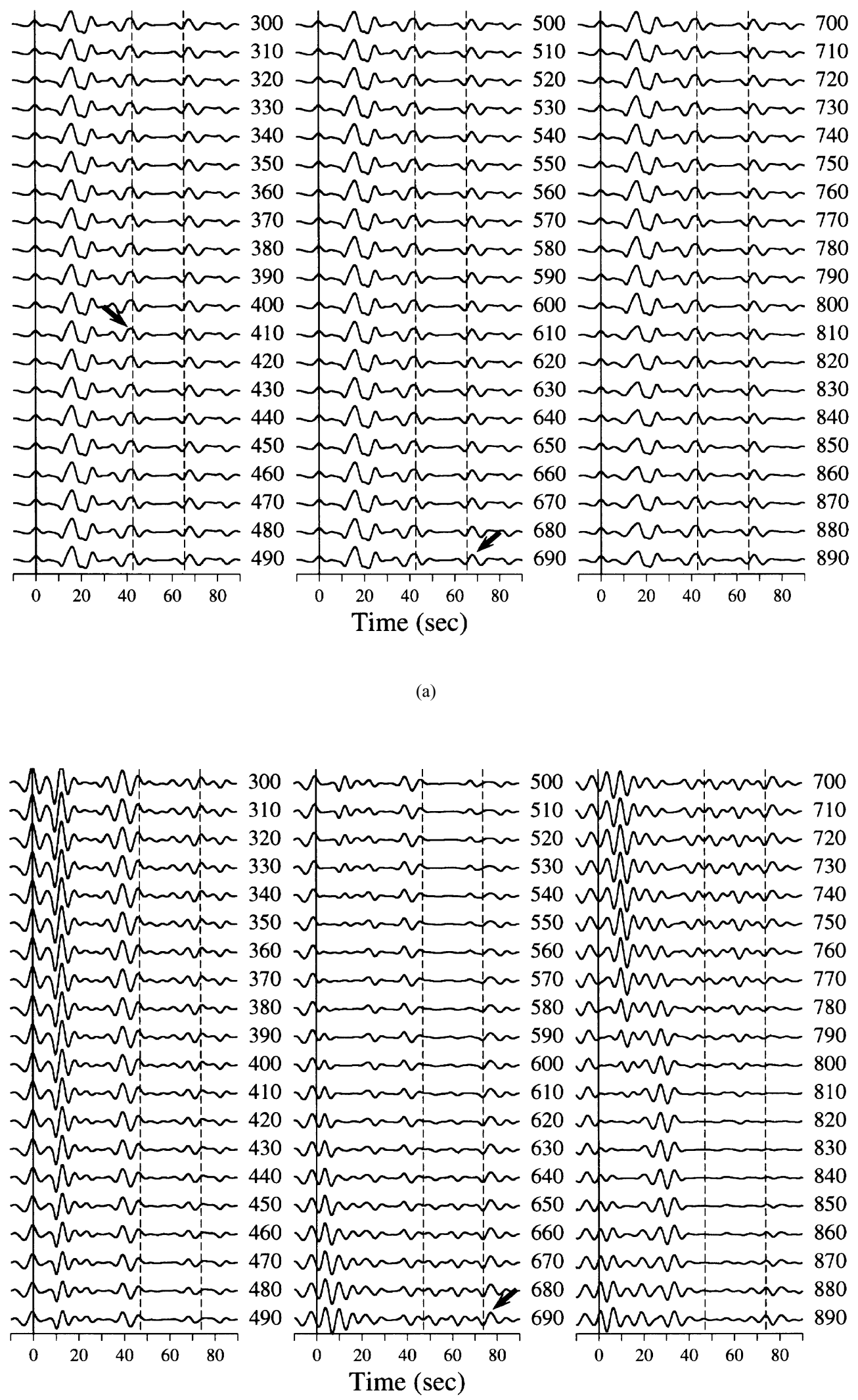

(b)

Fig. 5. (a) Stacked traces of the deep Tonga events at station BJI. The number to the right of each trace is the aligned depth in km (see text). Dashed lines are theoretical arrival time of $P_{410} s$ and $P_{660} s$ predicted by Iasp91. (b) The same as (a), but for non-Tonga events. Arrows indicate possible $P_{d} s$ candidates. 


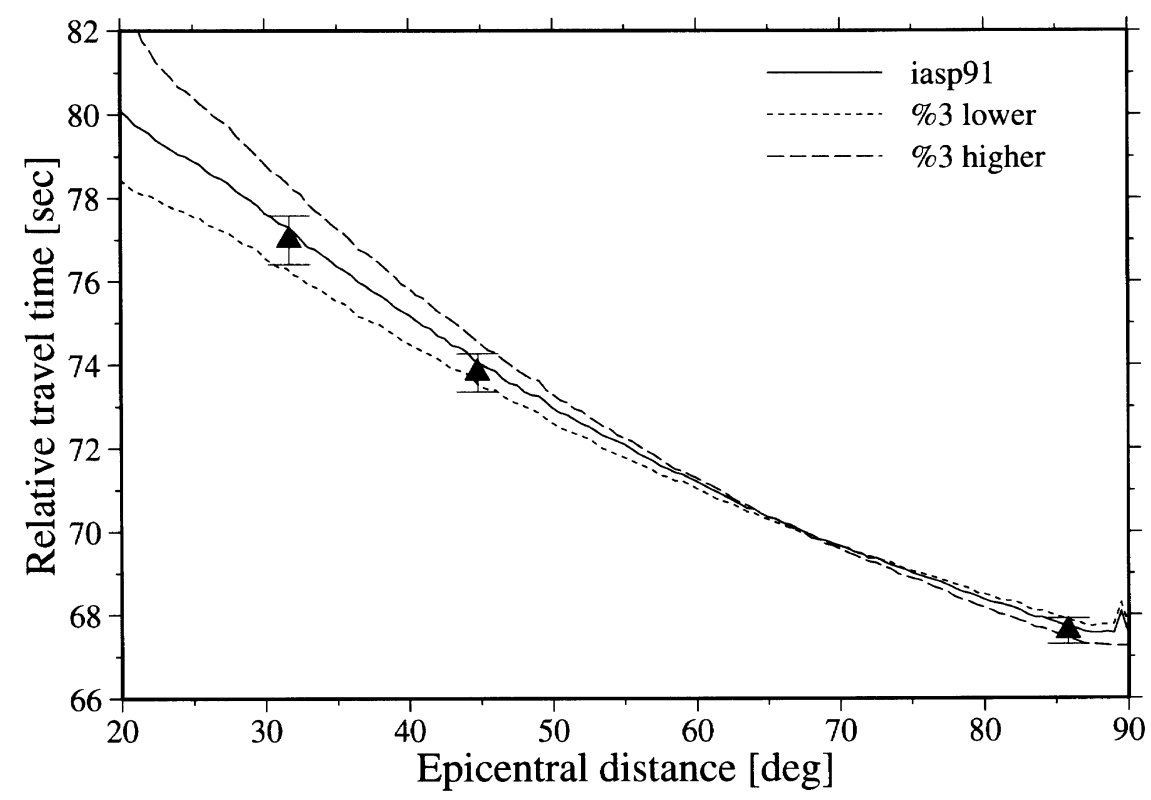

Fig. 6. Observed $\delta t_{P^{\prime} 660^{\prime}} s-P$ as a function of epicentral distance. The theoretical arrival time of $P_{690} s$ (solid line) for Iasp91 is shown with $P_{670} s$ (dotted line) and $P_{710} s$ (dashed line), predicted by two models with $3 \%$ higher and lower velocity upper mantle, respectively.

Table 1. Estimated depths and velocity models.

\begin{tabular}{|c|c|c|c|c|c|c|c|}
\hline $\begin{array}{l}\text { Station } \\
\text { code }\end{array}$ & Lon. & Lat. & $\begin{array}{c}\text { Events } \\
\text { used }\end{array}$ & $\begin{array}{l}\text { ‘410-km' } \\
\left(\begin{array}{ll}O & E\end{array}\right)^{\dagger}\end{array}$ & $\begin{array}{l}\text { '660-km' } \\
\left(\begin{array}{ll}O & E\end{array}\right)^{\dagger}\end{array}$ & $\begin{array}{c}\mathrm{TZ}^{*} \\
\left(\begin{array}{ll}O & E\end{array}\right)^{\dagger}\end{array}$ & Used model \\
\hline BJI & 116.1750 & 40.0400 & 29 & 400. 6. & $690 . \quad 2.5$ & 290. 6.5 & Iasp91 \\
\hline ENH & 109.4870 & 30.2720 & 24 & 410. 4. & $660 . \quad 6.5$ & $250 . \quad 7.5$ & Iasp91 \\
\hline HIA & 119.7420 & 49.2670 & 33 & 415. 12 & $665 . \quad 2.5$ & 250.12 .5 & revised ${ }^{\ddagger}$ \\
\hline KMI & 102.7400 & 25.1230 & 51 & 405. 4. & 650.6 & 245. 7.0 & revised ${ }^{\ddagger}$ \\
\hline LSA & 91.1500 & 29.7000 & 18 & 400. 6. & 660. 12. & 260. 13.5 & Iasp91 \\
\hline LZH & 103.8440 & 36.0870 & 25 & 395. 12 & 660.12 & 265. 17.0 & Iasp91 \\
\hline MDJ & 129.5920 & 44.6160 & 37 & 420. 12 & 670.6 & 250.13 .5 & revised ${ }^{\ddagger}$ \\
\hline QIZ & 109.8430 & 19.0290 & 11 & - & - & - & \\
\hline SSE & 121.1870 & 31.0960 & 18 & 395. 12 & 660.6. & 265.12 .5 & Iasp91 \\
\hline WMQ & 87.6950 & 43.8210 & 27 & 410. 4 & 665.6. & 255. 7.0 & Iasp91 \\
\hline XAN & 108.9210 & 34.0390 & 20 & - & - & - & \\
\hline
\end{tabular}

*: thickness of the transition zone. ${ }^{\dagger}:$ O, observed depth $(\mathrm{km})$; E, error $(\mathrm{km})$; —: not observed. ${ }^{\ddagger}$ : For station KMI, a 1.5\% lower velocity upper mantle is used, see text for detail of other stations.

tude of stacked waveforms for all 29 events is shown. The time scale of the horizontal axis is the equivalent depth of the assumed model, which is referred as "induced depth" to distinguish it from the "aligned depth" of the vertical axis. Hot color clusters located along the diagonal line can be regarded as candidate seismic discontinuities. The observed depths of '410-km' and '660-km' discontinuities are found to be $400 \mathrm{~km}$ and $690 \mathrm{~km}$, respectively. The deepening of the ' $660-\mathrm{km}$ ' discontinuity may be explained by a stagnant Pacific slab beneath eastern China as suggested by the tomographic model. As for the observed depth of $400 \mathrm{~km}$ for the
' $410-\mathrm{km}$ ' discontinuity, we must point out that this phase is confirmed at only one distance, therefore, having a trade-off between the depth and the reference model. However, since the average velocity model of the mantle above $660 \mathrm{~km}$ must be compatible with Iasp91, and if we assume that the HVAs in the transition zone is no larger than $3 \%$, then the permitted anomaly above the ' $410-\mathrm{km}$ ' discontinuity will be less than $1 \%$, introducing an error of less than $5 \mathrm{~km}$ on the inferred depth. Consequently, the observation suggests that the '410-km' discontinuity is elevated about $5-10 \mathrm{~km}$.

MDJ. We find $P^{\circ} 660^{\prime} s$ in the stacked seismograms (Fig. 8) 


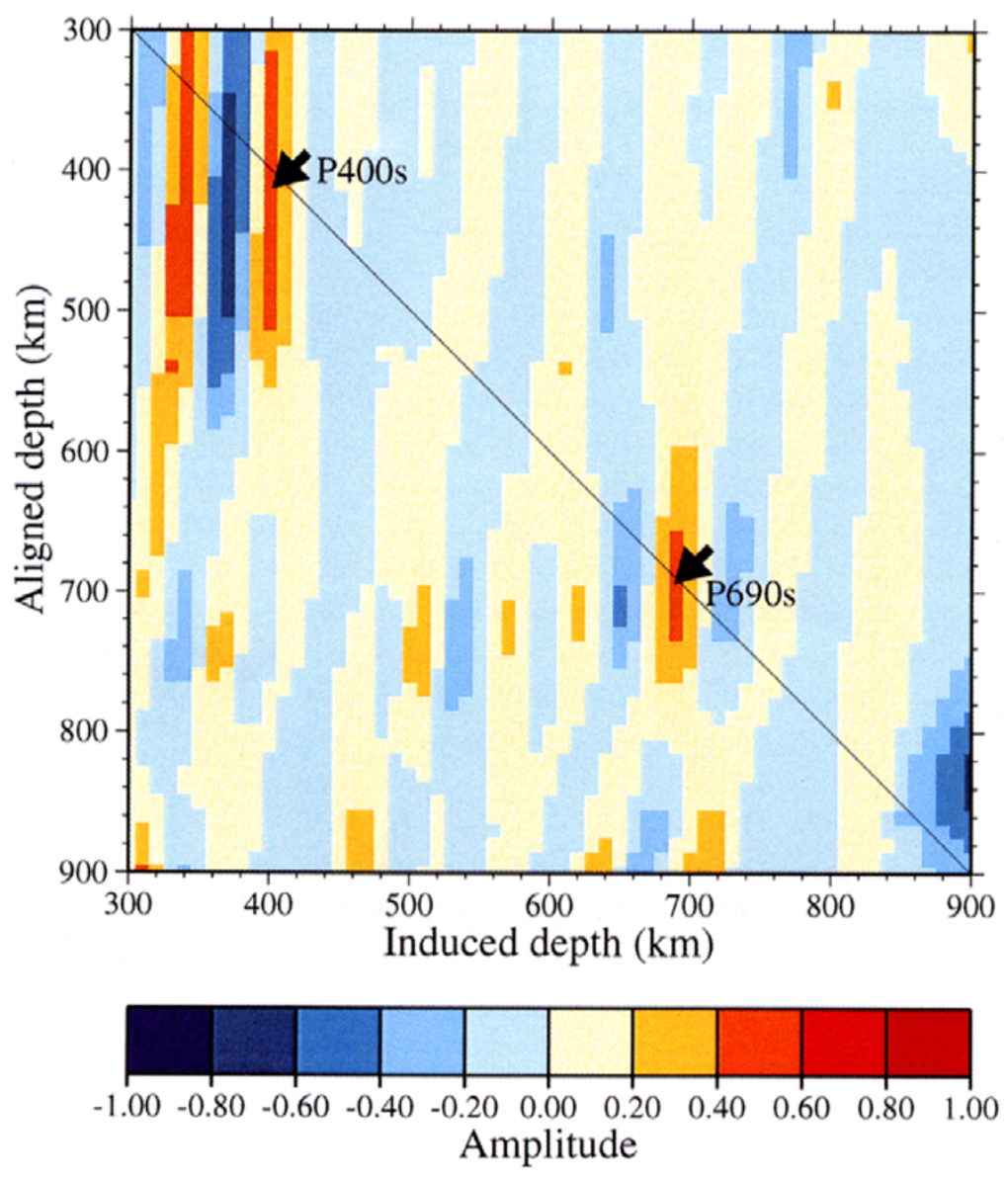

Fig. 7. Normalized amplitudes of stacked waveforms at BJI are plotted as a function of aligned depth (slowness) versus the P-to-S conversion depth, estimated by a reference model (see text). Note that only the hot color clusters located near the diagonal line can be regarded as candidates of seismic discontinuities.

of both the Tonga and non-Tonga groups at station MDJ (Heilongjiang Province). The observed $\delta t_{P^{\circ} 60^{\prime} s-P}$ times are plotted in Fig. 9. Theoretical travel time of $\delta t_{P_{670}-P}$ predicted by Iasp91 (solid line) and a revised Iasp91 (dashed line) with $1 \%$ lower upper mantle velocities above the ' $410-\mathrm{km}$ ' discontinuity and a $3 \%$ higher velocity transition zone are included. The revised Iasp91 is based on the tomographic model, and, is used as the reference model. Both models explain the observed $\delta t_{P^{\circ} 60^{\prime} s-P}$ data, however, there is a $5 \mathrm{~km}$ difference for the estimated depth of the ' $410-\mathrm{km}$ ' discontinuity. The determined depth of the ' $410-\mathrm{km}$ ' and the ' $660-\mathrm{km}$ ' discontinuities are $420 \mathrm{~km}$ and $670 \mathrm{~km}$, respectively. In Fig. 8(a), we can see another signal at approximately $82 \mathrm{sec}$ with polarity reversed from $P^{{ }^{\prime}} 660^{\prime} S$. We checked the individual seismograms in the stacking and confirmed that there should no primary phases arriving in this time window. Therefore, the signal is also a candidate P-to-S converted wave. The corresponding discontinuity would be at a depth of $850 \mathrm{~km}$, with a velocity decrease across it.

SSE. At station SSE (Shanghai), the total number of collected events is 18 , therefore we do not divide them into two groups. The stacked seismograms of the 18 events are shown in Fig. 10. We interpret the two signals at 42.1 and $68.1 \mathrm{sec}$ as $P^{{ }^{\prime}} 410^{\prime} S$ and $P^{\prime} 660^{\prime} S$. Since the average upper mantle velocity beneath SSE is almost same between the tomographic model and Iasp91, we therefore use Iasp91 as the reference model. The estimated depths of the ' $410-\mathrm{km}$ ' and ' $660-\mathrm{km}$ ' are $395 \mathrm{~km}$ and $660 \mathrm{~km}$. It is very interesting that a signal at $\sim 80 \mathrm{sec}$ can be seen in Fig. 10. After eliminating possible primary phase arrivals in the same window, we suggest that this is also a P-to-S wave converted at an approximate depth of $800 \mathrm{~km}$. This conclusion is, however, still preliminary due to the small number of seismograms in the stack.

\section{Results and Discussion}

As for the other CDSN stations, we can not find any significant depression or elevation of the discontinuities. As an example, we show the stacked waveform using all the events at station ENH in Fig. 11, two peaks at 43.4 and $66.8 \mathrm{sec}$ are identified to be $P^{{ }^{\prime}} 410^{\prime} s$ and $P^{\prime} 660^{\prime} S$. The determined depths are 410 and $660 \mathrm{~km}$, respectively.

Detailed depths of the '410-km' and '660-km' discontinuities observed at all the CDSN stations are listed in Table 1. Errors listed in Table 1 are calculated by the delete- $d$ jackknife method discussed in the last section. We must point out that it is difficult to distinguish between reference models which may produce difference in depth estimates as large as $5 \mathrm{~km}$ using real data. Therefore, the estimated errors of the depths of the '410-km' and '660-km' discontinuities as listed in Table 1 are optimistic and could be up to $5 \mathrm{~km}$ larger. 


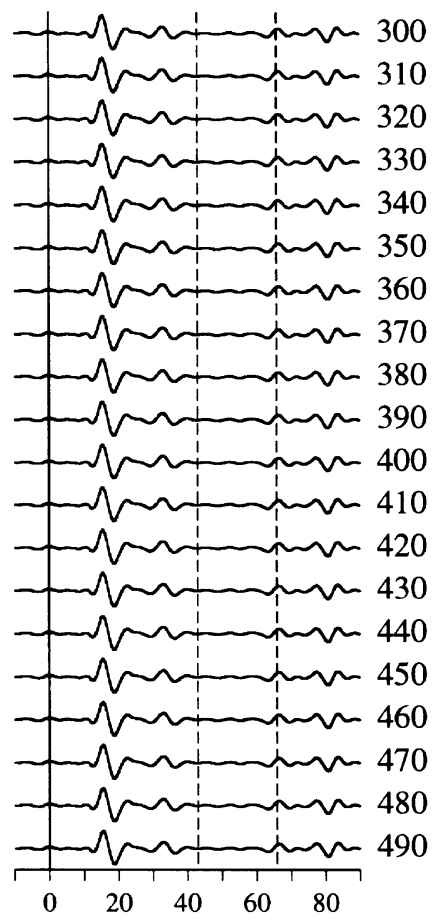

$\begin{array}{lllll}0 & 20 & 40 & 60 & 80\end{array}$

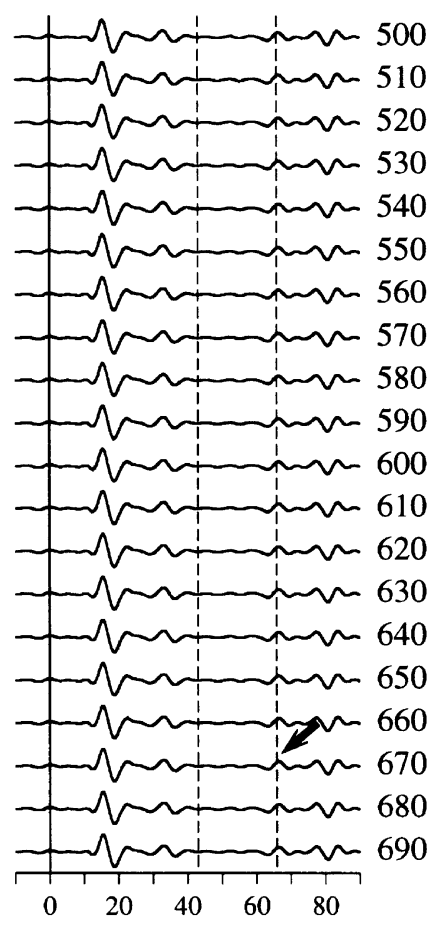

Time (sec)

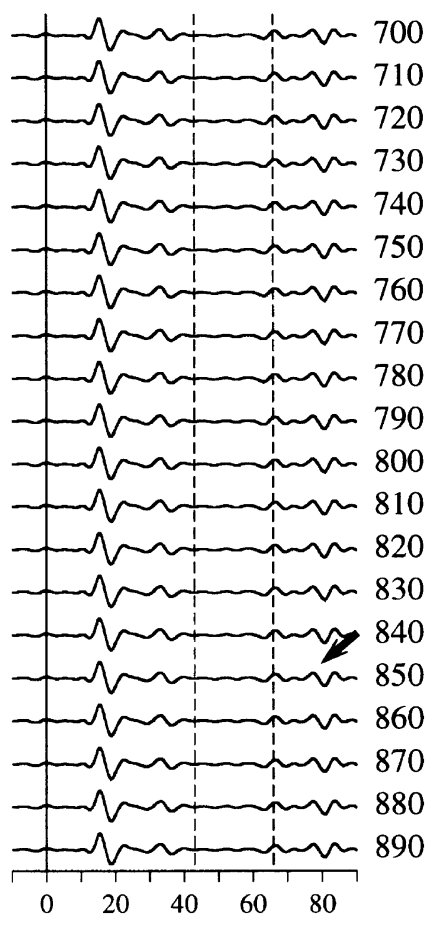

(a)

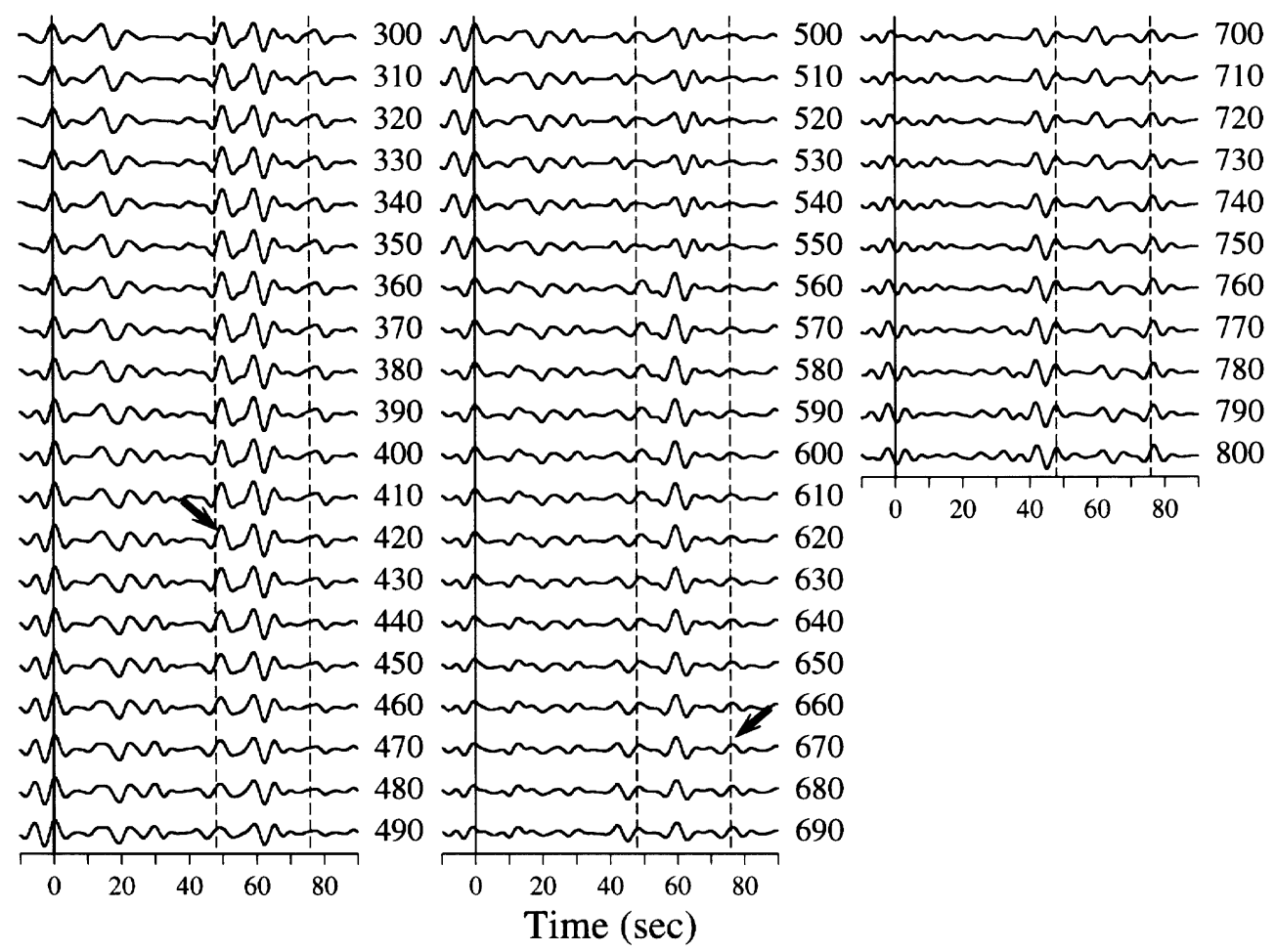

(b)

Fig. 8. Same with Fig. 5, but at station MDJ. 


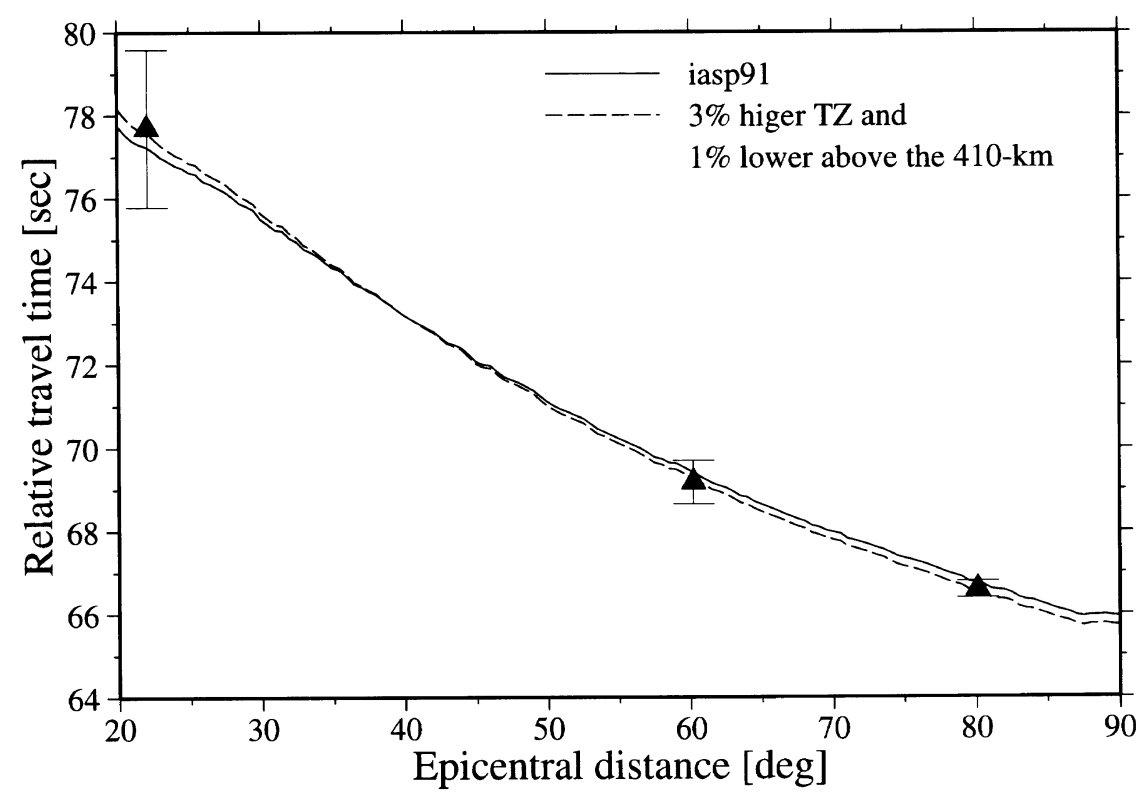

Fig. 9. Same with Fig. 6, but at station MDJ.

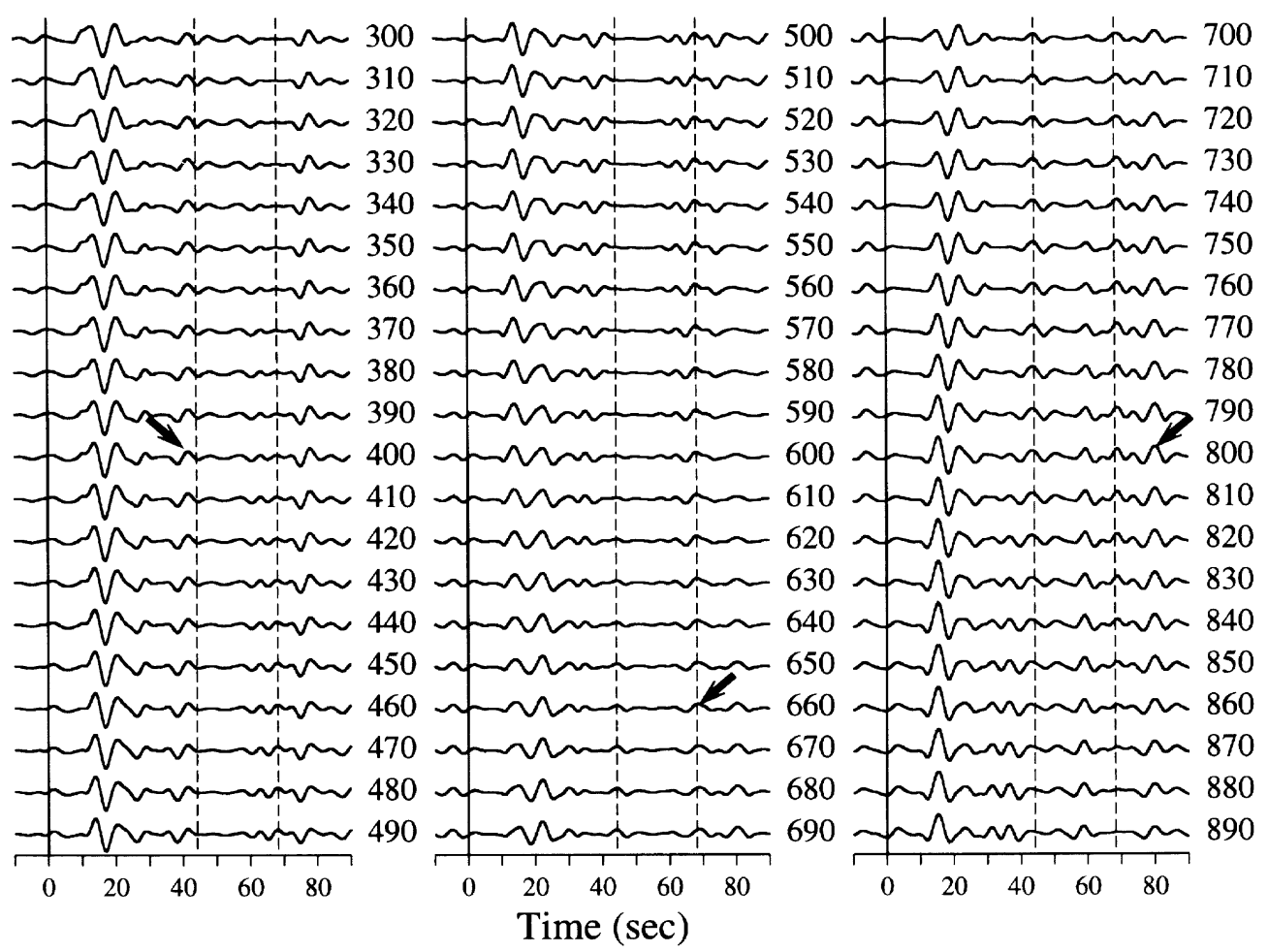

Fig. 10. Same with Fig. 5, but at station SSE for all events.

The estimated depth error of the ' $660-\mathrm{km}$ ' discontinuity at the most of the stations is, however, less than $10 \mathrm{~km}$.

Considering the possible error in the depth estimates, we can not observe evident depression or elevation of the '410$\mathrm{km}$ ' and the ' $660-\mathrm{km}$ ' discontinuities in the studied region, except beneath station BJI, where the ' $410-\mathrm{km}$ ' and ' 660 $\mathrm{km}$ ' discontinuities are elevated $10 \mathrm{~km}$ and depressed $30 \mathrm{~km}$, respectively. According to the mineral physics research, the phase changes responsible for the ' $660-\mathrm{km}$ ' seismic discontinuity is expected to occur at a higher pressure in a lower temperature circumstance due to its negative Clapeyron slope. As for the '410-km' discontinuity, the reverse is anticipated. Our results therefore indicate that the mantle transition zone beneath BJI is colder than average, suggesting that the sub- 

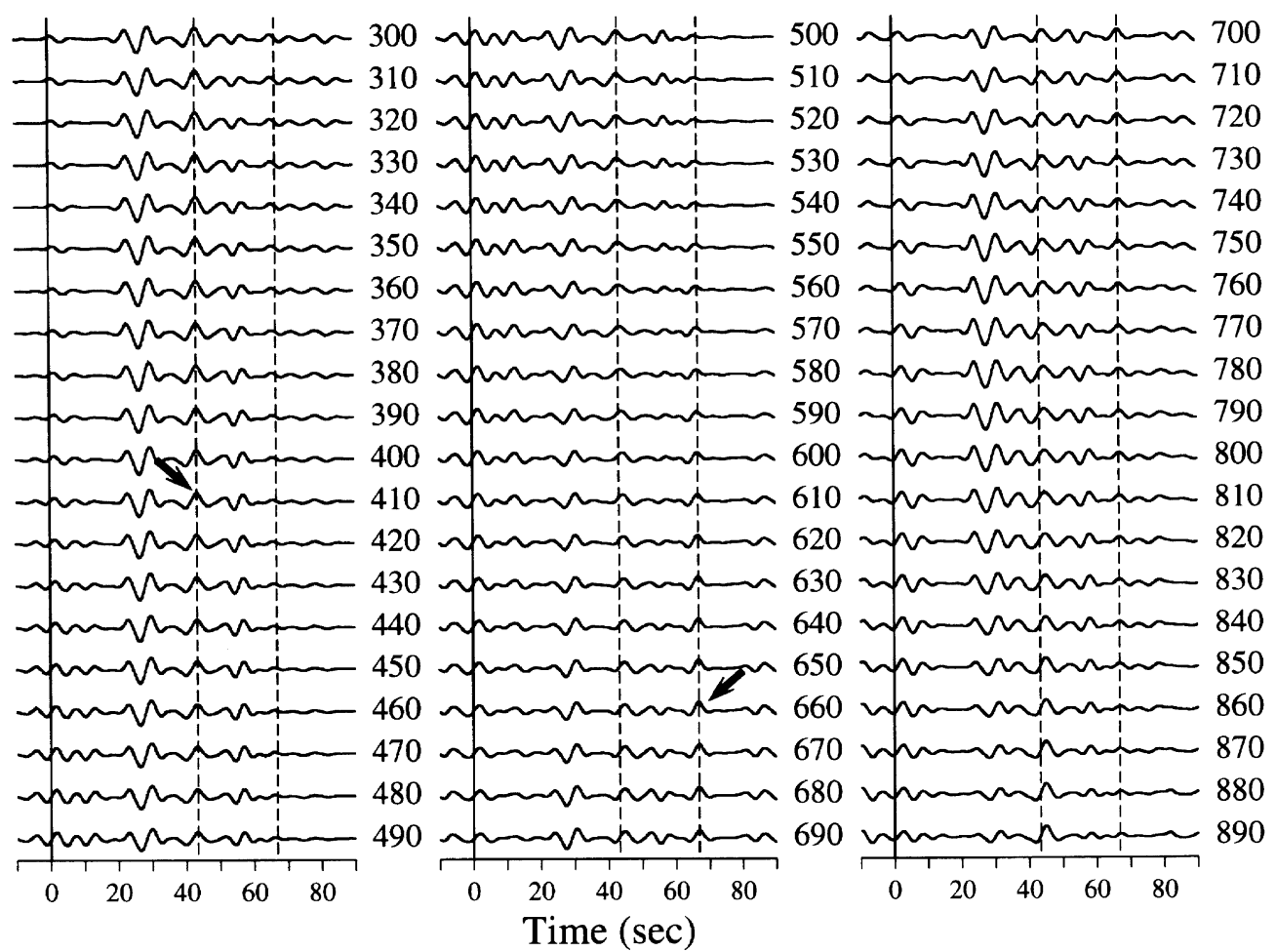

Fig. 11. Same with Fig. 5, but at station ENH for all events.

ducted Pacific plate exists east of Beijing in the Bohai sea region. Independent evidence that subducted Pacific plate exists in the same region is presented by the recent waveform study of Tajima et al. (1998).

For station MDJ, we observed a multiple-discontinuity structure at depths about 670,740 and $780 \mathrm{~km}$ when we inverted raw waveforms of deep Tonga events (Niu and Kawakatsu, 1996). Here, however, we do not see peaks at depths of 740 and $780 \mathrm{~km}$ in Fig. 8(a). Therefore the 740 and $780 \mathrm{~km}$ discontinuities seem to be local reflectors with very sharp velocity jumps. Meanwhile, the ' $660-\mathrm{km}$ ' discontinuity does not seem to be significantly depressed beneath the station MDJ. There are two HVAs in the tomographic model beneath MDJ, centered on the depths of approximately 500 and $800 \mathrm{~km}$, respectively. The HVA around the ' $660-\mathrm{km}$ ' discontinuity is not so strong, which may be the reason that discontinuity is not depressed much. The 740 and $780 \mathrm{~km}$ discontinuities seem to be small scale reflectors inside the subducted slab in the uppermost portion of the lower mantle, corresponding to the HVA at $800 \mathrm{~km}$ in the tomographic model. These discontinuities may be associated with non olivine phase transitions as suggested by Vacher et al. (1998). In that study, densities and seismic velocities of two temperature profiles, representing cold (subducting slabs) and average regions of the Earth's mantle are calculated according to available phase diagrams of mantle minerals. There are a total of three reactions that occur between a depth of 600 and $750 \mathrm{~km}: \gamma$-spinel $\rightarrow M g$-perovskite $+M g$-wüstite and garnet $\rightarrow$ ilmenite $\rightarrow$ perovskite. For the average temperature profile, the three reactions occur together near $660 \mathrm{~km}$. In the low temperature case, the three reactions occur at sep- arate depths. Vacher et al.'s calculation also suggests that the density and velocity increases of the three reactions are subequal.

The tomographic model suggests that HVAs exist in the transition zone depths beneath SSE. However, in Fig. 10, we do not find any depression of the '660-km' discontinuity, which means that there is no significant decrease of temperature. Therefore our result suggests that the HVAs do not exist around the ' $660-\mathrm{km}$ ' discontinuity, even though they do exist in the transition zone. In fact, in the tomographic model the HVAs beneath the station SSE are above the ' $660-\mathrm{km}$ ' discontinuity, centered at a depth of $500 \mathrm{~km}$. This may be why the ' $660-\mathrm{km}$ ' discontinuity is not depressed even though there is a HVA in the transition zone in the same region.

Vinnik et al. (1996) stack seismograms recorded by the easternmost Russia and 3 CDSN stations (BJI, HIA and MDJ) to detect the $P_{d} s$. The $30 \mathrm{~km}$ depression of the ' $660-\mathrm{km}$ ' discontinuity near BJI suggested by this study is absent in their result. The discrepancy is likely due to the lower lateral resolution of their study. Vinnik et al. (1996) stack all seismograms recorded by all the stations located in a region of $\sim 1000 \mathrm{~km}$ by $2000 \mathrm{~km}$, which may be regarded as the size of lateral resolution. On the other hand, we stack seismograms recorded in a single station and the P-to-S conversion points are located in a much smaller region (Fig. 2). As for HIA and MDJ, the results are consistent, that is no significant of depression of the ' $660-\mathrm{km}$ ' discontinuity are observed in these regions. Due to the sparse distribution of the CDSN stations (Fig. 2), we can not constrain the real lateral scale of $30-\mathrm{km}$ depression of the ' $660-\mathrm{km}$ ' discontinuity, but it should be in a region less than $\sim 1000 \mathrm{~km}$. Short-period studies suggest 
that the ' $660-\mathrm{km}$ ' discontinuity can be deepened up to $60 \mathrm{~km}$ in a region of 200-300 km wide (Richards and Wicks, 1990; Vidale and Benz, 1992; Wicks and Richards, 1993; Niu and Kawakatsu, 1995). Therefore we suggest that the trough of the ' $660-\mathrm{km}$ ' discontinuity in the studied region is likely to $\sim 30 \mathrm{~km}$ deep with a lateral scale of several hundreds kilometers, which is more consistent to the result of Neele et al. (1997).

\section{Conclusion}

We have developed a method to determine simultaneously the depth of a mantle discontinuity and the average velocity above it. The absolute depth of a discontinuity can be determined with an accuracy of approximately $\pm 10 \mathrm{~km}$ for the real data set. The method is applied to the broadband data of the CDSN stations. There is no significant depression of the '660-km' discontinuity except at station BJI. We do not find depression of the ' $660-\mathrm{km}$ ' discontinuity beneath the northeast China stations MDJ and HIA, which are located in 15 20-km-deep trough in the ' $660-\mathrm{km}$ ' discontinuity suggested by previous SS precursors studies (Shearer and Masters, 1992; Shearer, 1993; Flanagan and Shearer, 1998). Therefore the real lateral scale of the trough in the " 660 $\mathrm{km}$ ' discontinuity must be smaller. Beneath BJI, the ' 410 $\mathrm{km}$ ' and '660-km' discontinuities are elevated $10 \mathrm{~km}$ and depressed $30 \mathrm{~km}$, respectively, which results in an extremely thick transition zone. The phenomenon may be caused by the cold Pacific plate that exists in this region. Meanwhile, at the stations MDJ, where the subducted pacific plate is also found in the mantle transition zone depths, a multiple-discontinuity structure is observed rather than a depressed ' $660-\mathrm{km}$ ' discontinuity. At station SSE, we do not find any depression the ' $660-\mathrm{km}$ ' discontinuity, suggesting that there is no significant difference of temperature at depths around the $660 \mathrm{~km}$ between SSE and average mantle.

The different structures observed at the 3 stations suggest that either temperature or mantle mineral assemblage is different beneath the 3 stations, which may be attributed or due to the different dynamics of the subducted slabs after they penetrate the transition zone. Therefore a detailed investigation of the structure of the mantle transition zone discontinuities can help us to understand the behavior of subducted slabs which is important to the mantle dynamics.

Acknowledgments. We thank IRIS Data Management Center for supplying data; T. Sakurai, M. Obayashi and Y. Fukao for providing us their unpublished tomographic model; two anonymous reviewers for constructive reviews. One of the authors (Fenglin Niu) is supported by the Japan Society for the Promotion of Science.

\section{References}

Efron, E. and R. Tibshirani, Bootstrap methods for standard errors, confidence interval, and other measures of statistical accuracy, Statis. Sci., 1, 54-77, 1986.

Flanagan, M. P. and P. M. Shearer, Glabal mapping of the topography on the transition zone velocity discontinuities by stacking SS precursors, $J$.
Geophys. Res., 103, 2673-2692, 1998.

Fukao, Y., M. Obayashi, M. Inoue, and M. Nenbai, Subducting slabs stagnant in the mantle transition zone, J. Geophys. Res., 97, 4809-4822, 1992.

Grand, S. P. and D. V. Helmberger, Upper mantle shear structure of the North America, Geophys. J. R. Astr. Soc., 76, 399-438, 1984.

Haskell, N. A., Crustal reflections of the plane P and SV waves, J. Geophys. Res., 67, 4751-4767, 1962.

Kennett, B. L. N. and E. R. Engdahl, Travel times for global earthquake location and phase identification, Geophys. J. Int., 105, 429-465, 1991.

Koch, M., Bootstrap inversion for vertical and lateral variations of the $\mathrm{S}$ wave structure and the $v_{p} / v_{s}$-ratio from shallow earthquakes in the Rhinergraben seismic zone, Germany, Tectonophysics, 210, 91-115, 1992.

Neele, F., H. De Regt, and J. VanDecar, Gross errors in upper-mantle discontinuity topography from underside reflection data, Geophys. J. Int. 129, 194-204, 1997.

Niu, F. and H. Kawakatsu, Direct evidence for the undulation of the 660-km discontinuity beneath Tonga: Comparison of Japan and California array data, Geophys. Res. Lett., 22, 531-534, 1995.

Niu, F. and H. Kawakatsu, Complex structure of the mantle discontinuities at the tip of the subducting slab beneath the northeast China: a preliminary investigation of broadband receiver functions, J. Phys. Earth, 44, 701$711,1996$.

Petersen, N., J. Gossler, R. Kind, K. Stammler, and L. Vinnik, Precursors to SS and structure of transition zone of the north-western Pacific, Geophys. Res. Lett., 20, 281-284, 1993.

Revenaugh, J. and S. A. Sipkin, Mantle discontinuity structure beneath China, J. Geophys. Res., 99, 21911-21927, 1994.

Richards, M. A. and C. W. Wicks, Jr., S-P conversion from the transition zone beneath Tonga and the nature of the $670 \mathrm{~km}$ discontinuity, Geophys. J. Int., 101, 1-35, 1990 .

Sakurai, T., M. Obayashi, and Y. Fukao, Tomographic image of slab and mantle plume, Program and Abstracts, Seism. Soc. Japan, 1, 624, 1995 (in Japanese).

Shearer, P. M., Global mapping of upper mantle reflectors from long-period SS precursors, Geophys. J. Int., 115, 878-904, 1993.

Shearer, P. M. and T. G. Masters, Global mapping of topography on the 660 km discontinuity, Nature, 355, 791-796, 1992.

Tajima, F., Y. Fukao, M. Obayashi, and T. Sakurai, Evaluation of slab images in the northwestern Pacific, Earth Planets Space, 50, this issue, 953-964, 1998.

Vacher, P., A. Mocquet, and C. Sotin, Computation of seismic profiles from mineral physics: the importance of the non-olivine components for explaining the $660 \mathrm{~km}$ depth discontinuity, Phys. Earth Planet. Inter., 106 277-300, 1998 .

van der Hilst, R., R. Engdahl, W. Spakman, and G. Nolet, Tomographic imaging of subducted lithosphere below north-west Pacific island arcs, Nature, 353, 37-43, 1991.

Vidale, J. E. and H. M. Benz, Upper-mantle seismic discontinuities and the thermal structure of subduction zones, Nature, 356, 678-682, 1992.

Vinnik, L. P., Detection of waves converted from P to SV in mantle, Phys. Earth Planet. Inter., 15, 39-45, 1976.

Vinnik, L. P., G. Kosarev, and N. Petersen, Mantle transition zone beneath Eurasia, Geophys. Res. Lett., 23, 1485-1488, 1996.

Walck, M. C., The P-wave upper mantle shear structure beneath an active spreading center: the Gulf of California, Geophys. J. R. Astr. Soc., 76, 697-723, 1984.

Wicks, C. W., Jr. and M. A. Richards, A detailed map of the 660-kilometer discontinuity beneath the Izu-Bonin subduction zone, Science, 261, 1424-1427, 1993.

Zhou, H. W. and R. W. Clayton, P and S wave travel time inversions for subducting slab under the island arcs of Northeast Pacific, J. Geophys. Res., 95, 6829-6851, 1990.

F. Niu (e-mail: niu@eri.u-tokyo.ac.jp) and H. Kawakatsu (e-mail: hitosi@eri.u-tokyo.ac.jp) 